\title{
PENGARUH ORGANIZATIONAL AGILITY PERUSAHAAN DAN BUDAYA ORGANISASI TERHADAP NILAI PERUSAHAAN
}

\author{
Dede Jaelani \\ Sekolah Tinggi Ilmu Ekonomi STEMBI Bandung \\ Email: dedejaelani@stembi.ac.id
}

\begin{abstract}
Abstrak
Penelitian ini bertujuan untuk menguji dampak organizational agility perusahaan dan budaya organisasi terhadap nilai perusahaan. Metode penelitian yang digunakan adalah jenis metode kuantitatif. Metode pengambilan data sampel adalah purposive sampling Analsisis data dalam penelitian ini menggunakan uji validitas, uji reliabilitas, dan uji hipotesis. Berdasar hasil analisis data maka dapat disimpulkan bahwa: 1) Organizational Agility memiliki pengaruh psoitif dan signifikan terhadap nilai perusahaan manufaktur di Kabupaten Karawang dengan nilai C.R 5,843 dan nilai probabilitasnya sebesar 0,000 kurang dari 0,05; dan 2) Budaya Organisasi memiliki pengaruh positif dan siginifikan terhadap nilai Perusahaan manufaktur di kabupaten Karawang dengan nilai C.R 2,048 dan nilai probabilitasnya sebesar 0,042.
\end{abstract}

Kata Kunci: Pengaruh, Organizational Agility, Budaya Organisasi, Nilai Perusahaan.

\section{Abstract}

The purpose of this study is to determine the effect of corporate organizational agility and culture on corporate value. This study employed a quantitative research method. Purposive sampling was used to collect data. Validity, reliability, and hypothesis testing were used in this study's data analysis. The data analysis results indicate that: 1) Organizational Agility has a positive and significant effect on the value of manufacturing firms in Karawang Regency, with a C.R value of 5.843 and a probability value of 0.000 less than 0.05; and 2) Organizational Culture has a positive and significant effect on the value of manufacturing firms in Karawang district, with a C.R value of 2.048 and a probability value of 0.042 .

Keywords: Influence, Organizational Agility, Organizational Culture, Company Values.

\section{A. PENDAHULUAN}

Pesatnya perkembangan industri dalam beberapa tahun terakhir telah menciptakan masalah degradasi lingkungan (Li et al., 2018). Untuk memahami dan mengukur hubungan antara perkembangan industri dan kerusakan lingkungan, banyak peneliti telah mengembangkan kerangka teori dan model yang berbeda, termasuk studi tentang budaya organisasi (OC) dan kinerja lingkungan (Gondroduste \& Hilman, 2018). Namun, penting untuk mendukung kerangka kerja ini dengan bukti empiris. Peneliti sebelumnya telah menekankan budaya organisasi (OC) dan signifikansinya terhadap banyak aspek nilai perusahaan (El Ghoul \& Kim, 2017). Namun, ada sedikit penekanan pada pentingnya budaya organisasi dalam mengembangkan kinerja lingkungan perusahaan. Literatur terkini tentang OC dan keberlanjutan sebagian besar didasarkan pada studi kasus daripada data empiris (Elsbach \& Stigliani, 2018).

Pada abad 21 ini, perubahan terjadi sangat cepat dan dalam konteks yang sangat kompleks serta semakin meningkat. Organizational Agility sangat diperlukan oleh perusahaan, yaitu berupa kemampuan untuk beradaptasi dan berubah dalam waktu yang cepat sehingga mampu mengimbangi perubahan pasar (Brooks \& Oikonomou, 2018). Hal tersebut harus didukung oleh tinkgat ketangkasan perusahaan yang tinggi serta inovasi dalam berbagai bidang guna bertahan menghadapi pesaing baru, 
mengembangkan teknologi terbarukan, dan perubahan dalam waktu mendadak serta konteks yang menyeluruh (Nikpour, 2017).

Saat ini, perusahaan harus menghadapi lingkungan yang sangat bergejolak, karakteristik utamanya adalah tingkat ketidakpastian, kompleksitas, dan dinamisme yang tinggi (Pawirsosumarto et al.,2017). Jika perusahaan berusaha untuk bertahan hidup di lingkungan yang tidak stabil seperti itu, mereka harus mengembangkan kemampuan untuk mendeteksi perubahan lingkungan lebih awal dan untuk menawarkan jalan keluar serta strategi untuk tetap bertahan, mengembangkan peluang bisnis baru dan keunggulan dalam kemampuan kompetitif untuk dikembangkan lebih baik (Sunarsi, 2020). Dalam konteks ini, konsep kelincahan organisasi (OA) muncul sebagai salah satu isu utama yang menarik perhatian para peneliti dan praktisi.

OA telah didefinisikan sebagai kemampuan organisasi untuk merasakan perubahan lingkungan dan untuk menanggapinya secara efisien dan efektif. Dengan asumsi pandangan kemampuan dinamis (DCV) sebagai kerangka teoritis, OA adalah kemampuan dinamis kritis yang mempengaruhi tindakan kompetitif perusahaan dan oleh karena itu menjadi anteseden yang signifikan dari kinerja mereka (Lenz et al.,2017). Dalam nada ini, makalah ini mendekati OA sebagai kemampuan dinamis yang dapat digunakan organisasi dengan sengaja untuk mencapai dan mempertahankan keunggulan kompetitif dan untuk bertahan dari krisis dan lingkungan yang berubah (Kuzey \& Uyar, 2017).

OA perlu digabungkan serta dikembangkan dengan kemampuan sustainability perusahaan. OA adalah paradigma yang memungkinkan perusahaan untuk bertahan dalam lingkungan bisnis yang hiperkompetitif dan dinamis saat ini. Bersamaan dengan itu, perusahaan saat ini secara bertahap dituntut untuk lebih menghargai serta menempatkan lingkungan sesuai dengan kodratnya (Digdowiseiso, 2020; Zulmasyhur, 2018). Konkretnya, perusahaan didorong untuk menciptakan bisnis keberlanjutan dalam upaya meminimalkan dampak lingkungan perusahaan yang buruk. Dengan demikian, banyak perusahaan telah beralih ke desain dan pengembangan produk dan layanan ramah lingkungan dan penerapan proses yang lebih efisien lingkungan (Sugiyanto et al.,2018; Didowiseiso et al., 2020).

Saat ini, perusahaan menghadapi peraturan lingkungan karena aktivitas mereka menciptakan masalah lingkungan yang serius. Banyak perusahaan dipaksa untuk mengelola dan mengurangi jejak ekologis mereka untuk meningkatkan kinerja lingkungan mereka (Waluyo et al., 2019; Digdowiseiso \& Zainul, 2020). Dalam pengertian ini, ada sedikit penelitian tentang anteseden kinerja lingkungan perusahaan. Studi yang disebutkan di atas mengkonfirmasi bahwa meningkatkan pangsa pasar, meningkatkan reputasi perusahaan, meningkatkan biaya produksi dan tekanan kompetitif dapat menghasilkan strategi lingkungan (Sugiyanto et al., 2018).

Teori-teori yang berkembang sampai sekarang, seperti yang disebutkan di atas, lebih fokus pada tingkat makro. Namun, untuk pemahaman tingkat mikro yang lebih besar, penelitian harus didasarkan pada teori yang sebagian besar berpusat pada faktor internal individu perusahaan dan kontribusinya terhadap tujuan perusahaan itu sendiri. Selain itu, penelitian sebelumnya sebagian besar telah menetapkan hasil mereka dengan menggabungkan berbagai tingkat analisis dalam penelitian empiris (Digdowiseiso \& Sugiyanto, 2021). Studi-studi ini belum memberikan hasil yang baik dalam hal penelitian empiris karena temuan mereka tidak mencakup analisis dan penelitian tingkat perusahaan mikro. Oleh karena itu, ada kebutuhan untuk mempelajari di tingkat perusahaan dengan menggunakan norma dan nilai perusahaan dan karyawan yang berkaitan dengan praktik terbarukan (Suharyono \& Digdowiseiso, 2021). Penting bagi perusahaan untuk mempertimbangkan faktor-faktor tingkat mikro internal yang menjamin peningkatan kinerja lingkungan perusahaan. Dengan demikian, peran OC harus lebih diuji secara empiris. 
Jawa Barat merupakan provinsi dengan beberapa wilayah industri yang menjadi sentra dalam pengembangan manufaktur yang terintegrasi dengan ketersediaan infrastruktur di Pulau Jawa dan beberapa pulau lainnnya (Sugiyanto \& Digdowiseiso, 2017). Agus Gumiwang Kartasasmita yang menduduki jabatan Menteri Perindustrian mengatakan hal ini berdampak positif dalam meningkatkan efisiensi produksi dan logistik, sehingga meningkatkan daya saing produk (Rozandi \& Digdowiseiso, 2021).

Selain itu, sebagai provinsi yang menjadi kawasan industri terbesar serta terluasi di Indonesia, Jawa Barat menyumbang kntribusi yang tinggi terhadap PDRB yaitu dengan angka $41,81 \%$ pada kuartal II d tahun 2021. Tahun sebelumnya, Jawa Barat menyumbang Rp. 626 triliun (sekitar 14,05\% dari PDB nasional). Lahan total yang dimiliki oleh kawasan industri Jawa Barat mencapai 19.602,21 Ha. Hal ini terlihat antara lain dalam kasus di kota Tasikmalaya dan Sukabumi, dan 620 izin tambang yang telah resmi di keluarkan Pemerintah Provinsi Jawa Barat belum mendapat status clear.

Saat ini, konsep keberlanjutan merupakan konsep yang paling penting untuk diterapkan dalam operasional perusahaan (Taufik et al.,2021). Sustainability akan menggeser paradigma sebuah perusahaan, alih-alih lagi profit, tapi konsentrasi perusahaan itu sendiri. Perusahaan kini harus mulai fokus supaya langkah yang dilakukan agar bermanfaat bagi masyarakat di sekitar perusahaan tersebut (Minang et al.,2021; (Didowiseiso et al., 2020).

\section{B. LITERATURE REVIEW}

\section{Organizational Agility}

Gagasan kelincahan organisasi (Organizational Agility), seperti yang diusulkan oleh Waluyo et al. (2019) berakar pada dua konsep terkait yang dikembangkan sebelumnya (yaitu, kemampuan beradaptasi organisasi, aspek reaktif dan fleksibilitas organisasi, aspek proaktif). Secara konkret, OA mencakup kemampuan perusahaan untuk merasakan perubahan lingkungan dan meresponsnya dengan mudah dengan mengkonfigurasi ulang serangkaian sumber daya, proses bisnis perusahaan, dan strategi yang digunakan oleh perusahaan. Selain itu, Sambamurthy et al. (2018) menyatakan bahwa terdapat tiga dimensi yang saling terkait membentuk OA, yaitu: 1) Kelincahan Konsumen, hal ini melibatkan pemanfaatan pendapat konsumen untuk mendapatkan peningkatan pangsa pasar; 2) Kelincahan Bermitra, yang terdiri dari kemampuan perusahaan dalam menyerap pengetahuan dari mitra bisnis yang berbeda untuk meningkatkan respons perusahaan terhadap permintaan pasar; dan 3) Kelincahan Operasional, yang memerlukan desain ulang proses yang cepat untuk memanfaatkan kondisi lingkungan dan pasar yang snagat dinamis.

Selanjutnya, OA dapat dipahami sebagai sebuah kemampuan respons perusahaan, hal ini memungkinkan perilaku yang lebih efisien dalam lingkungan yang sangat mudah berubah dan permasalahan kompleks di dalamnya. Kondisi ini memerlukan reaksi cepat terhadap perubahan dan kemampuan perusahaan untuk mengantisipasi dan menangkap peluang, terutama melalui inovasi dan pembelajaran (Digdowiseiso \& Sugiyanto, 2018).

Dari pendekatan Dynamic Capabilities View (DCV), OA telah diidentifikasi sebagai kemampuan dinamis perusahaan. DCV adalah perpanjangan dari pandangan Berbasis Sumber Daya berdasarkan hasil penelitian Barney dan Peteraf, pandangan ini sangat diperlukan dalam menanggapi lingkungan yang sangat dinamis. Pendekatan RBV secara tradisional cenderung berfokus pada mekanisme internal organisasi tetapi kemampuan dinamis dipengaruhi oleh faktor lingkungan eksternal (Li et al.,2018).

Oleh karena itu, efektivitas kapabilitas dinamis dalam perusahaan bergantung pada konteks, meskipun informasi yang tersedia terbatas mengenai efek gabungan dari mekanisme internal dan eksternal organisasi. Nilai perusahaan-perusahaan ini semakin terletak pada penciptaan dan pemanfaatan pengetahuan, alih-alih jenis aset atau sumber daya lainnya (Goronduste \& Hilman, 2018). Dengan demikian, asumsi dapat dibuat bahwa nilai-nilai OC yang meningkatkan tingkat OA dalam suatu organisasi akan menemukan kondisi yang lebih menguntungkan dalam jenis konteks lingkungan untuk memberikan pengaruh positifnya. 
Dengan demikian, kondisi lingkungan ini akan secara positif mempengaruhi nilai kelincahan yang terlibat dalam salah satu dari empat tipologi OC yang berbeda, seperti yang dijelaskan di atas. Dalam kondisi seperti itu, nilai-nilai kelincahan organisasi akan tersebar luas. Berdasarkan uraian tersebut, dapat ditarik sebuah hipotesis sebagai berikut: $\mathrm{H} 1$ : Organizational Agility berpengaruh positif dan signifikan terhadap nilai perusahaan.

\section{Hubungan Tipologi OC ke OA}

Model CVF terdiri dari dua dimensi. Satu dimensi menekankan pada aspek fleksibilitas, kemampuan beradaptasi, dan dinamisme untuk menekankan stabilitas, ketertiban, dan kontrol. Sebaliknya, dimensi kedua menghadapkan orientasi internal yang berfokus pada integrasi, kolaborasi, dan inovasi, dengan orientasi eksternal yang berfokus pada diferensiasi dan persaingan (Elsbach \& Stigliani, 2018). Dikombinasikan bersama-sama terhadap satu sama lain, dimensi ini mengarah pada identifikasi empat jenis budaya khas (yaitu, budaya klan, budaya pasar, budaya adhocracy dan budaya hierarki) yang melibatkan karakteristik khusus dan khas. Di bawah ini adalah batasan konseptual singkat dari empat tipe budaya yang disajikan dalam Gambar 1 berikut:

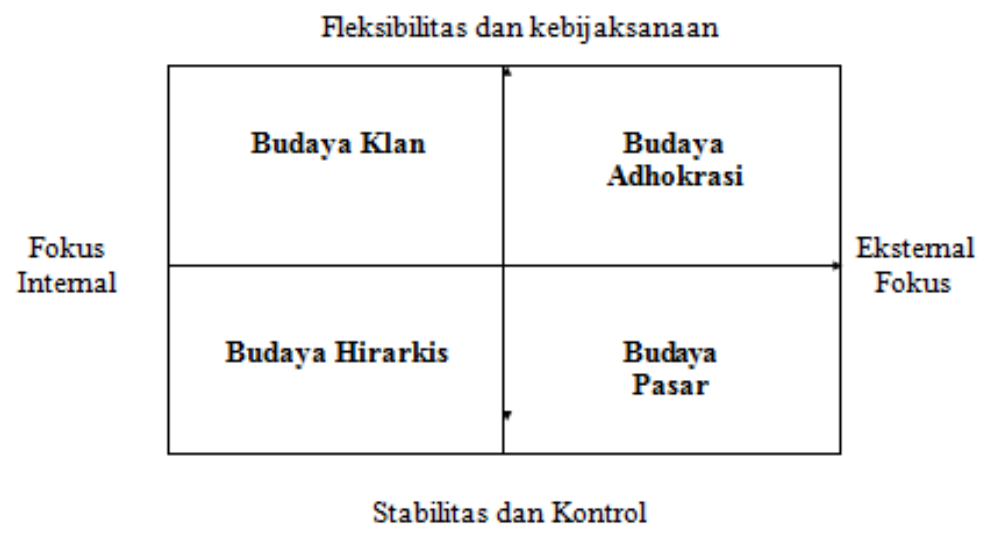

\section{Gambar 1. Kerangka Budaya Organisasi Perusahaan}

Budaya klan sering dikategorikan dengan ciri-ciri berikut: berorientasi pada keluarga, dapat dipercaya, kedekatan, pemberdayaan dan komunitas. Jenis budaya ini terutama berorientasi pada sumber daya manusianya, menekankan tingkat kesejahteraan individu dan mendorong suasana kerja yang positif yang terlalu mengoptimalkan rasio keuangan dan tujuan pasar. Perusahaan yang berbasis klan menggabungkan perhatian yang lebih rendah untuk struktur dan kontrol dan fokus yang lebih besar pada fleksibilitas (Li et al.,2018). Oleh karena itu, alih-alih aturan dan prosedur yang ketat, anggota perusahaan didorong melalui visi, tujuan bersama, dan hasil yang dirasakan bersama.

Budaya pasar diakui secara jelas berkaitan dengan tipe budaya pencapaian tujuan (atau objektif). Oleh karena itu, nilai-nilai utama perusahaan yang melekat pada budaya ini adalah produktivitas, efektivitas, daya saing, dan optimalisasi hasil. Perusahaan jenis ini biasanya menekankan perolehan prestise, status, profitabilitas serta tujuan utama mereka adalah untuk mengakhiri transaksi (yaitu, pertukaran, penjualan, kontrak), dengan pihak lain, dengan harapan mencapai keunggulan kompetitif. Dalam perusahaan jenis ini, baik transaksi internal maupun eksternal (pertukaran nilai) dipandang dari pangsa pasar (Sunarsi, 2020).

Budaya adhokrasi dapat dipahami sebagai kemampuan dinamis, kewirausahaan, inovatif, berani mengambil risiko, siap menghadapi perubahan, agresif, dan fleksibel. Perusahaan yang memiliki tipe budaya ini sering mengejar kesuksesan serta berfokus pada pengembangan inovasi, berkelanjutan dalam mengembangkan produk, layanan, dan proses yang inovatif. Oleh karena itu, ini adalah budaya yang paling berorientasi pada inovasi, yang target utamanya adalah menumbuhkan kemampuan beradaptasi, fleksibilitas dan kreativitas, untuk menghadapi ketidakpastian, ambiguitas, dan informasi yang berlebihan serta tidak 
diperlukan bagi perkembangan perusahaan (Goronduste \& Hilman, 2018).

Selanjutnya, budaya Hirarki biasanya digambarkan sebagai sangat budaya kaku dan birokratis, didorong oleh aturan dan diarahkan dari atas ke bawah. Pola dasar ini secara tradisional mencakup pendekatan yang menyoroti struktur dan kontrol dari rantai perintah yang ketat, seperti dalam teori birokrasi asli Max Weber. Budaya ini menekankan minimalisasi tingkat ambiguitas dan mempromosikan rasa aman, kepastian, prediktabilitas, efektivitas, stabilitas, formalisasi dan standardisasi yang intens. Jenis budaya ini mendukung perhatian jangka panjang untuk ketertiban dan mekanisme kontrol, diwujudkan dalam rentang norma, aturan, instruksi, dan prosedur yang eksplisit dan sangat tepat. Singkatnya, budaya ini fokus utamanya ada pada efisiensi dan pengendalian internal. Berdasarkan uraian tersebut, maka dapat ditariks beuah hipotesis sebagai berikut: H2: Budaya Organisasi berpengaruh positif dan signifikan terdapat nilai perusahaan.

\section{METODE}

Metode penelitian yang digunakan dalam penelitian ini adalah metode kuantitatif. Populasi yang digunakan dalam penelitian ini mencakup seluruh perusahaan yang bergerak dalam bidang manufaktur yang berada di Provinsi Jawa Barat periode tahun 2018 sampai dengan tahun 2020 yang berjumlah 1.695 perusahaan. Metode pengambilan sampel adalah purposive sampling dengan kriteria sebagai berikut: 1) Perusahaan yang bergerak dalam bidang manufaktu Jawa Barat, berbentuk Perseroan Terbatas dan tercatat di BEI periode 2018 sampai dengan 2020; 2) Perusahaan yang telah mengikuti Program Peringkat Kinerja Perusahaan dalam Pengelolaan Lingkungan dari KLHK dalam rentang 2020; dan 3) Melengkapi data yang tersedia. Jenis data yang digunakan dalam penelitian ini berjenis data sekunder. Analsisis pengolahan data menggunakan uji validitas, uji reliabilitas, dan uji hipotesis.

\section{HASIL DAN PEMBAHASAN}

Berdasarkan metode pemilihan sampel yang digunakan yaitu dengan metode purposive sampling, maka jumlah responden yang menjadi objek penelitian ini adalah 71 responden yang terdiri dari karyawan pada level top management, middle management dan lower management pada masing-masing perusahaan manufaktur di Kabupaten Karawang. Sebanyak 71 responden terpilih merupakan karyawan yang mewakili 5 perusahaan manufaktur yang mendapat peringkat PROPER di Kabupaten Karawang Jawa Barat. Seperti yang dijelaskan pada Tabel 1 di bawah ini:

Tabel 1. Data responden penelitian

\begin{tabular}{|c|c|c|}
\hline No & Nama Perusahaan & Jumlah Responden \\
\hline 1 & PT. Fahifa Prima Mandiri & 15 \\
\hline 2 & PT. Meindo Putra Perkasa & 15 \\
\hline 3 & PT. Yushiro Indonesia & 15 \\
\hline 4 & PT. Exedy Manufacturing Indoensia & 15 \\
\hline 5 & PT. Kongo Citra Manufaktur Indonesia & 11 \\
\hline Total & & 71 \\
\hline
\end{tabular}

Sumber: data diolah

\section{Uji Validitas}

Uji validitas ini menggunakan bantuan SPSS versi 26.0 for windows. Pengujian validitas ini digunakan untuk mengukur sejauh mana alat ukur yang digunakan valid untuk mengukur variabel penelitian, atau untuk mengukur sah dan tidaknya suatu kuisioner. Hasil uji validitas ditunjukkan pada Tabel 2 di bawah ini: 
Tabel 2. Hasil uji validitas

\begin{tabular}{|c|c|c|c|}
\hline Pertanyaan & t-count & $\mathbf{N}$ & Hasil \\
\hline 1 & 0,626 & 71 & Valid \\
\hline 2 & 0,625 & 71 & Valid \\
\hline 3 & 0,634 & 71 & Valid \\
\hline 4 & 0,620 & 71 & Valid \\
\hline 5 & 0,779 & 71 & Valid \\
\hline 6 & 0,791 & 71 & Valid \\
\hline 7 & 0,711 & 71 & Valid \\
\hline 8 & 0,758 & 71 & Valid \\
\hline 9 & 0,773 & 71 & Valid \\
\hline 10 & 0,796 & 71 & Valid \\
\hline 11 & 0,698 & 71 & Valid \\
\hline 12 & 0,748 & 71 & Valid \\
\hline 13 & 0,672 & 71 & \\
\hline 14 & 0,719 & 71 & \\
\hline
\end{tabular}

Sumber: data diolah

Berdasarkan data di atas, dapat ditunjukkan bahwa nilai pada kolom Corrected itemtotal (r-count) semuanya memiliki nilai lebih besar dari nilai r-tabel yaitu 0,234 yaitu diperoleh dari nilai persamaan $(\mathrm{df})=\mathrm{n}-2$, diketahui bahwa untuk total sampel (n) sebanyak 71. Berdasarkan hasil nilai pada r-tabel untuk df 69 dengan signifikansi 5\% sebesar 0,234. Berdasarkan uraian terrsebut maka dapat disimpulkan data tersebut sudah valid.

\section{Uji Reliabilitas}

Uji reliabilitas ini menggunakan SPSS versi 26.0 for Windows. Pengujian ini digunakan untuk menguji konsistensi sebuah kuisioner yang digunakan sebagai indikator sebuah variabel. Kuisioner tersebut dikatak reliabel jika kuisioner tersebut konsisten atau stabil dari satu uji ke uji lain. Hasil perhitungan ditunjukkan pada Tabel 3 berikut ini:

Tabel 3. Hasil uji reliabilitas

\begin{tabular}{|c|c|c|c|}
\hline Variabel & Nilai Cronbach Alpha & Titik Kritis & Keputusan \\
\hline Organizational Agility & 0,858 & 0,7 & Reliabel \\
\hline Budaya Organisasi & 0,934 & 0,7 & Reliabel \\
\hline Nilai Perusahaan & 0,956 & 0,7 & Reliabel \\
\hline
\end{tabular}

\section{Sumber: data diolah}

Hasil pengujian reliabilitas memiliki nilai Alpha Cronbach's sebesar 0,948. Guna mengetahui hasil pengujian reliabilitas ini mengacu pada penelitian yang dilakukan oleh Triton pada tahun 2005 yang mengklasifikasikan skala menjadi 5. Nilai Crobanch's Alpha sebesar 0,948 termasuk dalam skala 5 yaitu nilai Cronbach's Alpha sebesar 0,81 sampai dengan 1,00 yang artinya penelitian ini sangat dapat diandalkan atau reliabel.

\section{Pengujian Hipotesis}

Perlu dilakukan pengujian terhadap hipotesis yang telah diajukan guna mengetahui nilai kebenarannya dapat diterima atau ditolak. Hipotesis dianggap ditertima jika memiliki nilai Critical Ratio yang lebih besar dari 1,96 serta nilai probailitas lebih kecil dari 0,05 . Jika hipotesis yang diajukan tidak memenuhi kriteria tersebut maka tidak diterima. Hasil pengujian hipotesis disajikan dalam tabel berikut:

Tabel 3. Regression Weights

\begin{tabular}{|c|c|c|c|c|c|c|c|}
\hline \multicolumn{2}{|c|}{} & Estimate & S.E. & C.R. & P & Hasil \\
\hline $\begin{array}{c}\text { Organizational } \\
\text { Agility }\end{array}$ & $\rightarrow$ & Nilai Perusahaan & .273 & .058 & 5.843 & $* * *$ & Diterima \\
\hline Budaya Organisasi & $\rightarrow$ & Nilai Perusahaan & .187 & .057 & 2.048 & .042 & Diterima \\
\hline
\end{tabular}


Sumber: data diolah

\section{H1: Organizational Agility berpengaruh positif dan signifikan terhadap nilai perusahaan}

Berdasarkan hasil Tabel 3, diketahui bahwa nilai C.R (critical ratio) untuk mengetahui pengaruh variabel Organizational Agility terhadap variabel nilai perusahaan adalah 5,843 lebih besar dari persyaratan yaitu 1,96 dan nilai probabilitasnya sebesar 0,000 kurang dari 0,05. Maka dapat disimpulkan bahwa organizational agility berpengaruh positif dan siginifikan terhadap nilai Perusahaan manufaktur di kabupaten Karawang Artinya hipotesis $\mathrm{H} 1$ dapat diterima.

Alasan yang dapat menjelaskan hal tersebut berdasarkan hasil analisis laporan tahunan perusahaan manufaktur di Kabupaten Karawang bahwa ditemukan nilai kepatuhan yang minim terutama dalam hal denda serta sankjsi moneter yang harus diterima sebagai akibat dari timbulnya masalah lingkungan. Sehingga dapat disimpulkan, semakin rendah peran perusahaan dalam mematuhi aspek kepatuhan terhadap peraturan perundang-undangan lingkungan maka semakin kecil nilai perusahaan yang diterima (Lenz te al.,2017). Hal ini dikarenakan, sekarang investor mulai selektif dalam menentukan sebuah perusahaan yang dipilih sebagai tempat investasi. Maka dalam hal ini investor lebih antusias untuk investasi dalam perusahaan yang memeiliki manajemen guna menjaga keseimbangan alam serta tidak merugikan lingkunangan yang diakibatkan oleh kegiatan produksi perusahaan tersebut (Kuzey \& Uyar, 2017).

Secara keseluruhan, maka dapat diambil kesimpulan bahwa kinerja lingkungan yang telah dilakukan oleh perusahaan yang bergerak dalam bidang manufaktur di Kabupaten Karawang cukup baik dan manfaat yang diperoleh dinilai baik dari aspek internal maupun eksternal perusahaan. Namun berdasarkan hasil survey dan wawancara ditemukan beberapa hal yang perlu diperhatikan dan ditingkatkan dalam kinerja lingkungan perusahaan manufaktur di Kabupaten Karawang.

\section{H2: Budaya Organisasi berpengaruh positif dan signifikan terhadap nilai perusahaan}

Berdasarkan hasil Tabel 3, diketahui bahwa nilai C.R (critical ratio) untuk mengetahui pengaruh variabel Budaya Organisasi terhadap variabel nilai perusahaan adalah 2,048 lebih besar dari persyaratan yaitu 1,96 dan nilai probabilitasnya sebesar 0,042 kurang dari 0,05. Maka dapat disimpulkan bahwa budaya organisasi berpengaruh positif dan siginifikan terhadap nilai Perusahaan manufaktur di kabupaten Karawang, artinya hipotesis $\mathrm{H} 2$ dapat diterima.

Budaya organisasi terdiri dari keyakinan, nilai, norma, kebiasaan dan praktik dalam sebuah organisasi. Beradasarkan hasil penelitian yang dilakukan oleh Brooks \& Oikonomou (2018) mendefinisikan konsep tersebut sebagai sistem norma, nilai bersama, perhatian, dan keyakinan umum yang dipahami dan diterima oleh anggota organisasi. Anggota organisasi menerima ini sebagai hal yang sah, mengikutinya dan mengajarkannya kepada anggota yang masuk sebagai pola yang harus diikuti untuk pemecahan masalah dan sebagai gaya berpikir dan perilaku yang diperlukan. Pendatang baru di suatu organisasi mungkin membawa harapan sebelumnya tentang budaya ketika mereka bergabung, tetapi budaya juga ditransmisikan kepada pendatang baru oleh staf yang sudah mapan, terkadang secara eksplisit tetapi lebih sering secara implisit. Budaya organisasi dibentuk dan diartikulasikan tidak hanya oleh individu tetapi juga oleh fitur organisasi baru dan lama. Struktur organisasi, rutinitas, harapan komando dan kontrol, dan norma operasional semuanya memiliki pengaruh (Nikpour, 2017). Hal ini tentu akan memberikan nilai lebih bagi perusahaan manufaktur di kabupaten Karawang. Di sisi lain, budaya organisasi tampaknya menjadi faktor penting dalam memahami kemampuan setiap organisasi untuk tampil dan bersaing dalam pasar yang terus berubah secara dramatis. 


\section{E. KESIMPULAN}

Berdasarkan hasil data penelitian dan analisis, dapat disimpulkan bahwa: 1) Organizational Agility berpengaruh positif dan signifikan terhadap nilai perusahaan manufaktur di Kabupaten Karawang dengan nilai C.R 5,843 dan nilai probabilitasnya sebesar 0,000 kurang dari 0,05; dan 2) Budaya Organisasi berpengaruh positif dan siginifikan terhadap nilai Perusahaan manufaktur di kabupaten Karawang dengan nilai C.R 2,048 dan nilai probabilitasnya sebesar 0,042 .

\section{DAFTAR PUSTAKA}

Brooks, C., \& Oikonomou, I. (2018). The effects of environmental, social and governance disclosures and performance on firm value: A review of the literature in accounting and finance. The British Accounting Review, 50(1), 1-15.

Digdowiseiso, K. (2020). The Development of Higher Education in Indonesia. International Journal of Scientific \& Technology Research, 9(2).

Digdowiseiso, K., \& Sugiyanto, E. (2018). Causality on the Growth-Governance-Fiscal Decentralization Nexus: An Analysis of Time Series in Indonesia. Journal of Applied Economic Sciences, $13(7$ (61)).

Digdowiseiso, K., \& Sugiyanto, E. (2021). How Effective is Institutional Quality for the Creation of Small \& Medium Enterprises (SMEs) in Indonesia?. Economics \& Sociology, 14(1), 263-274.

Digdowiseiso, K., \& Zainul, D. (2020). Fiscal Decentralization in District of Karawang, Indonesia. International Journal of Scientific \& Technology Research, 9(2).

Digdowiseiso, K., Setiawan, H. D., Sugiyanto, E., \& Suharyono, S. (2020). Does leadership matter in managing the village-owned enterprise?. Opción: Revista de Ciencias Humanas y Sociales, (93), 115-135.

Digdowiseiso, K., Sugiyanto, E., \& Setiawan, H. D. (2020). Business Licensing and the Indonesia's Master Plan 2011-2025. International Journal of Scientific \& Technology Research, 9(01).

Digdowiseiso, K., Sugiyanto, E., \& Setiawan, H. D. (2020). Fiscal Decentralisation and Inequality in Indonesia. Экономика региона. 2020. Том. 16, выпуск 3, 16(3), 9891002.

Digdowiseiso, K., Sugiyanto, E., \& Setiawan, H. D. (2020). Fiscal Decentralisation and Inequality in Indonesia. Экономика региона. 2020. Том. 16, выпуск 3, 16(3), 9891002.

El Ghoul, S., Guedhami, O., \& Kim, Y. (2017). Country-level institutions, firm value, and the role of corporate social responsibility initiatives. Journal of International Business Studies, 48(3), 360-385.

Elsbach, K. D., \& Stigliani, I. (2018). Design thinking and organizational culture: A review and framework for future research. Journal of Management, 44(6), 2274-2306.

Gorondutse, A. H., \& Hilman, H. (2018). Does organizational culture matter in the relationship between trust and SMEs performance. Management Decision.

Kuzey, C., \& Uyar, A. (2017). Determinants of sustainability reporting and its impact on firm value: Evidence from the emerging market of Turkey.Journal of cleaner production, 143, 27-39.

Lenz, I., Wetzel, H. A., \& Hammerschmidt, M. (2017). Can doing good lead to doing poorly? Firm value implications of CSR in the face of CSI. Journal of the Academy of Marketing Science, 45(5), 677-697.

Li, Y., Gong, M., Zhang, X. Y., \& Koh, L. (2018). The impact of environmental, social, and governance disclosure on firm value: The role of CEO power. The British Accounting Review, 50(1), 60-75. 
Minang, H. P., Digdowiseiso, K., \& Sugiyanto, E. (2021). Pelaksanaan Kebijakan Alokasi Dana Desa Dalam Memperdayakan Masyarakat Desa: Studi Kasus Desa Caturtunggal, Kecamatan Depok, Kabupaten Sleman. Ilmu dan Budaya, 42(73).

Nikpour, A. (2017). The impact of organizational culture on organizational performance: The mediating role of employee's organizational commitment. International Journal of Organizational Leadership, 6, 65-72.

Pawirosumarto, S., Sarjana, P. K., \& Gunawan, R. (2017). The effect of work environment, leadership style, and organizational culture towards job satisfaction and its implication towards employee performance in Parador Hotels and Resorts, Indonesia. International Journal of Law and Management.

Rozandi, M., \& Digdowiseiso, K. (2021). Implementasi Penggunaan Dana Desa Terhadap Pembangunan (Studi Kasus Desa Sengkubang Kecamatan Mempawah Hilir Provinsi Kalimatan Barat). Jurnal Sosial dan Humaniora, 6(1), 47-62.

Sugiyanto, E., \& Digdowiseiso, K. (2017). Revisiting the Aid-Growth Nexus: New Evidence on 56 Least Developed Countries. J. Advanced Res. L. \& Econ., 8, 1950.

Sugiyanto, E., \& Digdowiseiso, K. (2019). Do incidence and duration of child labour matter on schooling in Indonesia?. International Journal of Education Economics and Development, 10(1), 22-35.

Sugiyanto, E., Digdowiseiso, K., Waluyo, T., \& Setiawan, H. D. (2018). The Effects of Specific Allocation Fund (DAK) on Local Economic Development: A Mixed Method Analysis on Central Java Province, Indonesia. Journal of Applied Economic Sciences, 13(8 (62)), 1-9.

Sugiyanto, E., Djumadin, Z., \& Digdowiseiso, K. (2018). Irrigation planning in the era of local autonomy: an analysis of existing and alternative model. J. Advanced Res. L. \& Econ., 9, 692.

Suharyono, S., \& Digdowiseiso, K. (2021). Education and gender wage gap: Evidence from Indonesia. Accounting, 7(1), 33-40.

Suharyono, S., \& Digdowiseiso, K. (2021). The Effects of Environmental Quality on Indonesia's Inbound Tourism. International Journal of Energy Economics and Policy, 11(1), 9.

Sunarsi, D. (2020). The Analysis of The Work Environmental and Organizational Cultural Impact on The Performance and Implication of The Work Satisfaction. Jurnal Ilmiah Ilmu Administrasi Publik, 9(2), 237-246.

Taufik, A., Sugiyanto, E., \& Digdowiseiso, K. (2021). Analisis Kesehatan Keuangan Daerah Kabupaten/Kota Se Provinsi Banten Tahun Anggaran 2016-2019. Ilmu dan Budaya, 42(73).

Waluyo, T., Digdowiseiso, K., \& Sugiyanto, E. (2019). The Costs of Reduction Emission from Deforestation and Forest Degradation. Concepts and Issues. Journal of Environmental Management \& Tourism, $10(1$ (33), 636-72.

Waluyo, T., Digdowiseiso, K., \& Sugiyanto, E. (2019). The Costs of Reduction Emission from Deforestation and Forest Degradation. Concepts and Issues. Journal of Environmental Management \& Tourism, $10(1$ (33)), 636-72.

Zulmasyhur, Z. (2018). Reexamining the economic growth-education inequality-income distribution nexus in Indonesia. Journal of Applied Economic Sciences (JAES), 13(58), 979-988. 